\title{
ARTICLE OPEN Single-bubble water boiling on small heater under Earth's and low gravity
}

\author{
Ezinwa Elele ${ }^{1}$, Yueyang Shen ${ }^{1}$, John Tang ${ }^{1}$, Qian Lei ${ }^{1}$ and Boris Khusid (D)
}

Today's trends for enhancing boiling heat transfer in terrestrial and space applications focus on removal of bubbles to prevent formation of a vapor layer over the surface at high overheat. In contrast, this paper presents a new boiling regime that employs a vapor-air bubble residing on a small heater for minutes and driving cold water over the surface to provide high heat flux. Singlebubble boiling of water was investigated under normal gravity and low gravity in parabolic flights. Experiments demonstrated a negligible effect of gravity level on the rate of heat transfer from the heater. Due to self-adjustment of the bubble size, the heat flux provided by boiling rose linearly up with increasing heater temperature and was not affected by a gradually rising water temperature. The fast response and stable operation of single-bubble boiling over a broad range of temperatures pave the way for development of new devices to control heat transfer by forming surface domains with distinct thermal properties and wettability. The bubble lifetime can be adjusted by changing the water temperature. The ability of heating water on millimeter scales far above $100^{\circ} \mathrm{C}$ without an autoclave or a powerful laser provides a new approach for processing of biomaterials and chemical reactions.

npj Microgravity (2018)4:21; doi:10.1038/s41526-018-0055-y

\section{INTRODUCTION}

Miniaturization of electronic and photonic systems is challenged by a dramatic increase in the power dissipation per unit volume with the occurrence of hot spots where the heat flux is much higher than the average. Force-flow cooling by gas or liquid appears insufficient to remove local high heat fluxes. ${ }^{1,2}$ Boiling that involves evaporation of liquid in a hot spot and condensation of vapor in a cold region can remove a significantly larger amount of heat through the latent heat of vaporization. ${ }^{3}$ It is therefore considered as the most promising cooling technology for future microgravity applications. ${ }^{4,5}$ Boiling begins at a certain value of the heater temperature, termed the onset of nucleate boiling, with the appearance of bubbles in surface imperfections. The classical scenario of the pool boiling on Earth under normal gravity, $g_{E}$, in which a heater is submerged in a stagnant liquid is that a bubble, once formed, will grow driven by liquid evaporation and detach from the surface. ${ }^{3}$ As the bubble departs, a hot liquid is pushed away from the surface and replaced with a cooler liquid from the bulk. An increase in the heater temperature, $T_{\mathrm{h}}$, activates more nucleation sites and accelerates the vapor production, bubble growth and departure. The nonlinear nature of these phenomena causes the heat flux $q_{\mathrm{h}}$ to rise rapidly with the heater superheat ${ }^{6,7}$ as $q_{\mathrm{h}} \sim\left(T_{\mathrm{h}}-T_{\text {sat }}\right)^{\mathrm{m}}$, where $T_{\text {sat }}$ is the liquid saturation temperature at a given pressure and $\mathrm{m}$ ranges from 3 to 5 . Eventually the heat flux reaches a maximum (termed the critical heat flux) when bubbles growing in adjacent cites merge together and cover the heater surface with vapor. Heat transfer is then drastically reduced as the heated surface is totally blanketed with an insulating vapor film. ${ }^{3}$

Extensive studies of nucleate boiling on small heaters were conducted over the past two decades under normal gravity, low gravity and hypergravity. ${ }^{8-18}$ It was demonstrated that the relative contribution of the buoyancy and surface tension to the energy transfer away from the heater can be characterized by the ratio of the characteristic heater size $L_{h}$ to the capillary length $L_{c}=$ $\sqrt{\gamma_{1} / g\left(\rho_{1}-\rho_{v}\right)}$ specified by the liquid surface tension $\gamma_{1}$, liquid $\rho_{1}$ and vapor $\rho_{\mathrm{v}}$ densities, and gravity acceleration $\mathrm{g}$. The classical scenario of boiling occurs at a sufficiently large $L_{h} / L_{c}$ (large heaters or high gravity) when the buoyancy facilitates removal of bubbles from the surface. A threshold depends on the heater geometry and liquid properties. Boiling at small $L_{h} / L_{c}$ (small heaters or low gravity) is dominated by capillary forces and thermocapillary convection around bubbles. ${ }^{15-18}$ Nucleated bubbles in this case are observed to slide over the heater, detach (even in microgravity due to the vapor recoil) and hover close to the heater, coalescing with satellite bubbles. ${ }^{8-18}$ Once bubbles form a vapor layer covering the heated surface, heat transfer is dramatically reduced.

The appearance of a vapor film on the surface at high superheat is the bottleneck to the performance of boiling heat transfer on relatively large and small heaters. Accordingly, current methods for heat transfer enhancement focus on removal of bubbles to prevent the creation of a vapor film..$^{3-5,10-12,18}$ In contrast, we present a new boiling regime of water in which a vapor-air bubble anchored to a small heater for minutes at temperature up to about $280^{\circ} \mathrm{C}$ provides a heat flux up to $\sim 1.2 \mathrm{MW} / \mathrm{m}^{2}$, even though this value lies within the range of maximum heat fluxes on horizontal surfaces under normal gravity. ${ }^{3}$

\section{RESULTS}

The conditions of experiments carried out in parabolic flights and on Earth are listed in (SI1). Low gravity measurements were conducted in 3 days of parabolic flights in NASA Boeing 727. A flight provided two sets of consecutive parabolic arcs, each with 15 -s freefall at acceleration $\sim 10^{-2} \mathrm{~g}_{\mathrm{E}}$ preceded and followed by periods of acceleration $\sim 1.3 \mathrm{~g}_{\mathrm{E}}$ for $50-60 \mathrm{~s}$ where $\mathrm{g}_{\mathrm{E}}$ is the normal

${ }^{1}$ Otto H. York Department of Chemical, Biological \& Pharmaceutical Engineering, New Jersey Institute of Technology, Newark, NJ, USA

Correspondence: Boris Khusid (boris.khusid@njit.edu)

Received: 11 September 2017 Revised: 2 August 2018 Accepted: 7 August 2018

Published online: 02 November 2018 


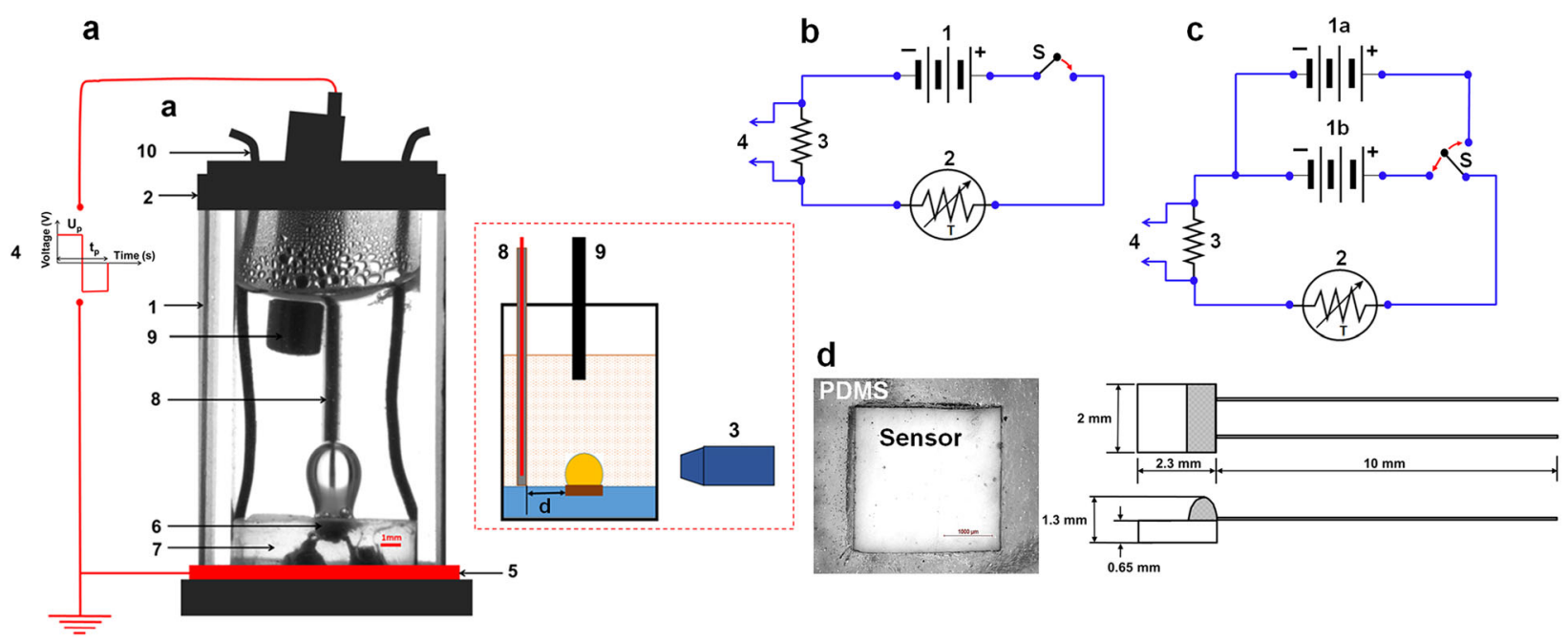

Fig. 1 Cell: a Front and side views: 1, cuvette with liquid; 2, cover; 3, camera, signal recorded by a laptop over the entire experiment; 4 , connection to amplifier for generating high voltage pulses of alternating polarity; 5 , grounded electrode; 6 , temperature resistance sensor (heater); 7, PDMS slab; 8, energized electrode coated with Teflon at $2 \mathrm{~mm}$ from the heater, 9, temperature probe in ground experiments; 10 , connection to heating circuit. Electrical circuits: b flight: 1, heating DC power source; c Earth: 1a, heating DC power source; $1 \mathrm{~b}, 3 \mathrm{~V}$ DC power source; S, switch; (both b, c) 2, heater; 3, resistor; 4, connection to acquisition system; d photo of platinum sensor P0K1.232.4 W.B.010 in PDMS slab whose silver wires (diameter $0.25 \mathrm{~mm}$, length $10.0 \mathrm{~mm}$ ) were soldered to power lead copper wires (Gauge 36 copper wire, length 4 mm); sensor sketch reproduced with permission from Innovative Sensor Technology, Las Vegas, NV

a
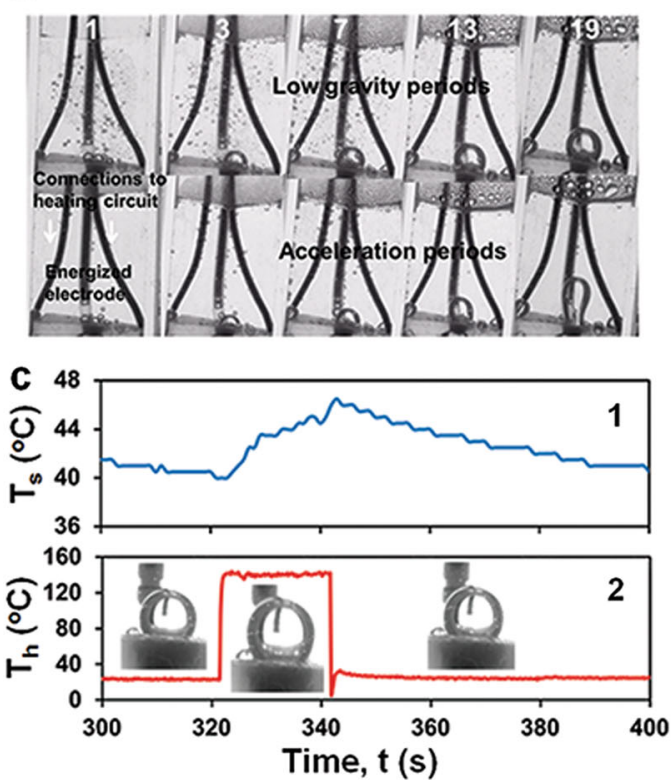

b

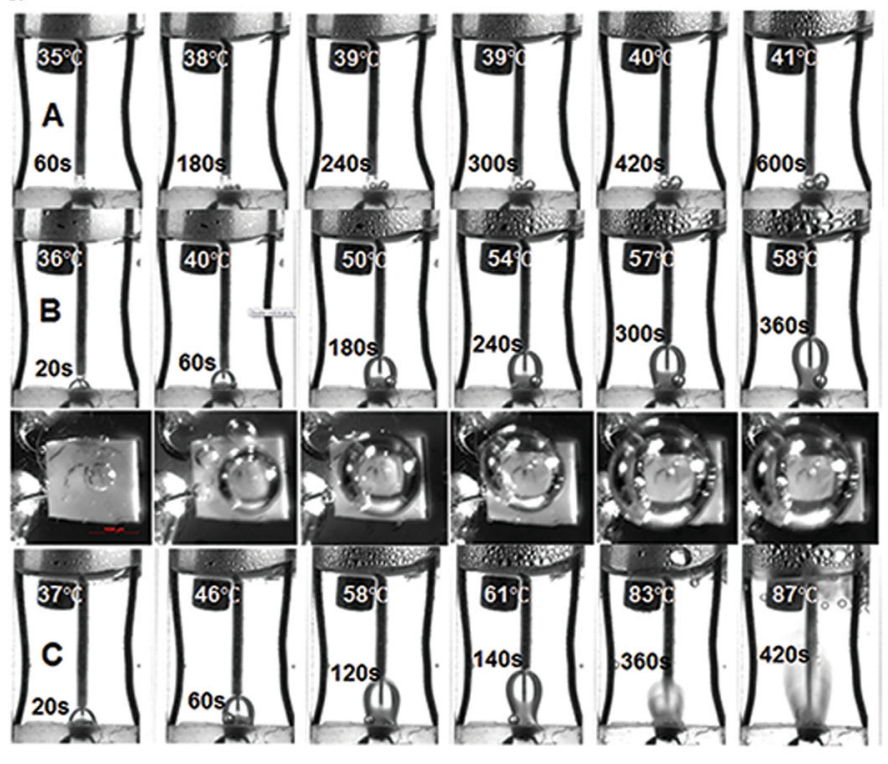

Fig. 2 Thermal regimes: a Flight, parabolas (number shown); $22.4 \mathrm{~V}$ DC \& $4 \mathrm{kV} / 20 \mathrm{~Hz}$ pulses applied in freefall (top row) and switched off during acceleration (bottom row); b Earth, continuous heating, no HV pulses; $\mathrm{T}_{\mathrm{s}}$ and heating time shown; applied V DC: 10 (A); 20 (B); 30 (C) see heat flux for A, B, C in Fig. 4a. c Earth, heating cycles $20 \mathrm{~V} \mathrm{DC} \mathrm{\&} 4 \mathrm{kV} / 20 \mathrm{~Hz}$ pulses $20 \mathrm{~s}$ on/60 s off, temperatures: 1, $T_{\mathrm{s}} ; 2$, $\mathrm{T}_{\mathrm{h}}$

gravity acceleration; the second set also included two parabolas simulating the gravity of the Moon $\left(1.62 \mathrm{~m} / \mathrm{s}^{2}\right)$ and Mars $(3.71 \mathrm{~m} /$ $\mathrm{s}^{2}$ ). Following guidelines, ${ }^{19}$ a flight setup was designed to withstand "crash g-forces" up to $9 \mathrm{~g}_{\mathrm{E}}$ along horizontal axis, up to $2 \mathrm{~g}_{\mathrm{E}}$ along positive vertical axis and up to $6 \mathrm{~g}_{\mathrm{E}}$ along negative vertical axis (Supplementary information, SI1). The setup was equipped with two cuvettes shown in Fig. 1 for simultaneous testing of different liquids. Experiments were carried out on $3 \mathrm{M}$ Novec HFE-7100 (3 M, St. Paul, MN) and distilled water from a local pharmacy with conductivity $\sigma_{\mathrm{I}} \sim 2 \cdot 10^{-4} \mathrm{~S} / \mathrm{m}$ and dielectric constant $\varepsilon_{1} \sim 78$ measured before experiments. Here we present data only for water. Due to the limited space of the paper, experiments on HFE-7100 for which a conventional boiling regime was observed will be reported elsewhere. For water at room temperature, $L_{c}$ equals $2.7 \mathrm{~mm}$ on Earth and $27 \mathrm{~mm}$ for freefall. A cuvette (Fig. 1) was loaded with $1 \mathrm{~mL}$ of water and then closed with a plastic lid. As a liquid in a cooling system utilized over a long period of time usually accumulates dissolved air, experiments were carried out with the cuvette lid that was not airtight to maintain atmospheric pressure inside the cuvette. A platinum temperature resistance sensor, serving as a heater, was embedded into a polydimethylsiloxane (PDMS) slab such that the heating surface was in contact with water (Fig. 1d). The ratios of the heating surface width and length (Fig. 1d) to the capillary length 
were respectively $0.74,0.85$ for experiments on Earth and 0.074 , 0.085 in flight. The interior contact angles of water on the heater surface and PDMS measured at room temperature were respectively $74 \pm 3^{\circ}$ (hydrophilic) and $107 \pm 2^{\circ}$ (hydrophobic). The heater was connected in series with a resister $\mathrm{R}_{0}$ and a direct current (DC) power source that provided voltage $U_{D C}$ to the heater (Fig. 1). The voltage drop across this resistor $U_{R}$ was measured to compute the voltage drop on the heater $\Delta \mathrm{U}_{\mathrm{h}}=\mathrm{U}_{\mathrm{DC}}-\mathrm{U}_{\mathrm{R}}$, the electrical current $I_{\mathrm{h}}=U_{\mathrm{R}} / R_{0}$, the power $I_{\mathrm{h}} \Delta U_{\mathrm{h}}$ that varied from about $0.5 \mathrm{~W}$ to $5.5 \mathrm{~W}$ and the heater resistance $R_{\mathrm{h}}=\Delta U_{\mathrm{h}} / I_{\mathrm{h}}$ that was used for calculating its temperature $T_{\mathrm{h}}$ from the linear calibration curve $R_{\mathrm{h}}$ vs. $T_{\mathrm{h}}$. The values of heat flux $q_{\mathrm{h}}=I_{\mathrm{h}} \Delta U_{\mathrm{h}} / S_{\mathrm{h}}$ reported in Figs. 2-6 correspond to the total power provided to the heater. Expressions ${ }^{20}$ were used to estimate the heat loss from the heater through the power lead wires and directly into the PDMS slab. Calculations presented in SI1 indicate that the heat loss increased with raising the heater temperature from about $9 \%$ at $T_{\mathrm{h}} \approx 50{ }^{\circ} \mathrm{C}$ to $13 \%$ at $T_{\mathrm{h}} \approx 270{ }^{\circ} \mathrm{C}$. Additional two parameters were measured on Earth due to flight limitations: (i) the temperature $T_{s}$ slightly below the water surface by probe 9 in Fig. 1a to estimate the bulk liquid temperature and (ii) the heater temperature $T_{\mathrm{h}}$ when the heating power source was turned off by applying $3 \mathrm{~V} \mathrm{DC}$ to the heater (Fig. 1c). For the latter, the generated power $\sim 0.075 \mathrm{~W}$ might raise the heater temperature by $\sim 2^{\circ} \mathrm{C}$.

Since electric fields are widely used to enhance boiling heat transfer, ${ }^{18,21-24}$ the cuvette was equipped with electrodes to investigate the field effects on single-bubble boiling. Conventional electric techniques are limited to low conducting liquids because of using bare electrodes inserted into the liquid. To avoid this limitation, a train of successive rectangular high-voltage (HV) pulses of alternating polarity, $U_{p}=3-4 \mathrm{kV}$ at frequency $1 / \mathrm{t}_{\mathrm{p}}$ up to $100 \mathrm{~Hz}$, was applied to water via the insulated energized electrode inserted into the water and the grounded electrode placed under the cuvette (Fig. 1a). The power supplied by HV pulses was less than $0.2 \mathrm{~W}$ (SI1). As the electric stress exerted on a liquid is proportional to the square of the field strength, the application of these pulses kept the electric stress at a constant level. The motion of charge carriers in a liquid subjected to an electric field depends on the ratio ${ }^{25}$ between the charge relaxation time $t_{\mathrm{rel}}=\varepsilon_{0} \varepsilon_{1} / \sigma_{1}$ and the period of HV pulses $t_{\mathrm{p}}$, where $\varepsilon_{0}$ is the vacuum permittivity. As $t_{\text {rel }} \sim 5 \mu s \ll t_{\mathrm{p}}$ in our experiments, ions in water followed the field, thereby reducing the accumulation of charge due to voltage reversals. The proposed design offers the ability of applying an electric force to liquids with much higher electrical conductivity as the chance of short circuit, sparking, and electrocorrosion are drastically reduced.

All flight heating tests were performed in the presence of HV pulses (SI1). Heating DC voltage $20 \mathrm{~V}$ or $22.4 \mathrm{~V}$ and HV pulses were simultaneously turned on when the aircraft began to freefall. Once the aircraft began to accelerate, they were turned off to avoid the contribution of buoyancy and electric field driven convection. They were also turned off as the aircraft maneuvered for about 10 min to begin flying the second set of parabolas.

A large bubble rapidly formed on the heater during the first freefall. Its footprint was gradually increasing in size, until anchoring on the heater edges after a couple of minutes. It was staying on the heater over the first set of parabolas and detached during the acceleration period of one of parabolas during the second set (Fig. 2a, SI2, video1). Specifically, a bubble formed in the first freefall was remaining on the heater for total of 20 parabolas (32 $\mathrm{min})$ in the first flight, $27(41 \mathrm{~min})$ in the second flight and 19 parabolas $(36 \mathrm{~min}$ ) in the third flight. As the firstly formed bubble detached, another one formed and stayed on the heater until the end of the flight. During a freefall, a bubble staying on the heater emitted sporadically tiny bubbles that were carried away with the flow. As the aircraft was accelerating, these tiny bubbles rose to the water surface and popped up due to buoyancy. The heater temperature and heat flux during a freefall period stabilized within $2 \mathrm{~s}$ after applying DC voltage. Variations of heat flux values from parabola to parabola measured at the same heating regime were lying within 2-4\% (SI1).

Experiments on Earth were carried out under conditions of continuous heating and heating cycles with DC voltage $20 \mathrm{~s}$ on/ $60 \mathrm{~s}$ off (SI1). Variations of heat flux values measured at the same heating regime were lying within 1-6\% (SI1). A consistent performance of single-bubble boiling was observed for both heating modes. To avoid rapid deterioration of the PDMS slab around the heater, most experiments were conducted for heater temperatures below $270^{\circ} \mathrm{C}$. Photos in Fig. $2 \mathrm{~b}$ illustrate bubbles formed under continuous heating. Tiny bubbles appeared on the heater at $10 \mathrm{~V} \mathrm{DC}$ for which $\mathrm{T}_{\mathrm{h}}$ was below $100^{\circ} \mathrm{C}$ (Fig. 2b, regime A) were mainly due to the release of air dissolved in water as its solubility decreased with temperature. A single bubble formed on the heater when $T_{h}$ was above $100^{\circ} \mathrm{C}$. Side and top images in Fig. $2 \mathrm{~b}$ B show the evolution of the first bubble appeared at $20 \mathrm{~V} \mathrm{DC}$. The first bubble formed at $30 \mathrm{~V} D C$ is shown on images in Fig. $2 \mathrm{~b}$ regime $C$ from 20 to $140 \mathrm{~s}$. As can be seen in Fig. $2 \mathrm{~b}$ regimes $B$ \& $C$, the bubble foot gradually expanded until reaching the heater edge. While the heater temperature $T_{h}$ and heat flux $q_{h}$ stabilized within several seconds after applying DC voltage, the bulk temperature of water for both heating modes gradually rose due to the low rate of heat transfer out of the cuvette. This feature was used to investigate the effect of water temperature on singlebubble boiling. The timescale of changes in water temperature $T_{s}$ for continuous heating was about 5 min for voltage greater than $10 \mathrm{~V}$ DC (SI1). The amplitude of water temperature variation in a heating cycle was in the range $2-6^{\circ} \mathrm{C}$, gradually increasing with applied DC voltage. The timescale of changes in water temperature from cycle to cycle were much smaller than that for continuous heating since the electric power averaged over a cycle was four times smaller. Plots and photos in Fig. 2c illustrate variations of $T_{\mathrm{h}}, T_{\mathrm{s}}$ and the bubble size in a typical heating cycle. When the heater temperature dropped down once the heating was off, the bubble shrank due to condensation of water vapor (Fig. $2 \mathrm{a}$ in flight and Fig. $2 \mathrm{c}$ on Earth). While the heater temperature and heat flux did not change in the process of boiling, the height $h$, volume $V$, and cap surface area $S$ of the pinned bubble were gradually increasing due to the rising water temperature (Fig. 3a-d). Fig. 3e, fillustrates a change in the bubble volume $\Delta V$ caused by vapor condensation after the heating was turned off and the air volume fraction in the bubble (calculated as $1-\Delta V / V$ ) with the number $N$ of heating cycles.

Points $A, B, C$ in Fig. 4a mark regimes shown in Fig. 2b. The maximum efficiency of HV pulses was achieved at $20 \mathrm{~Hz}$ (Fig. $4 \mathrm{a}$ inset) at which the heat flux increased by about $10 \%$ at the same heater temperature. In flight and in both heating modes on Earth, the heat flux $q_{\mathrm{h}}$ of a pinned bubble was found to rise linearly to 1.2 MW/m $/ \mathrm{m}^{2}$ with increasing heater temperature $T_{\mathrm{h}}$ to about $280^{\circ} \mathrm{C}$ as (Fig. $4 \mathrm{a}, \mathrm{SI} 1$ )

$q_{\mathrm{h}}\left(\mathrm{kW} / \mathrm{m}^{2}\right)=(4.63 \pm 0.15)\left(T_{\mathrm{h}}-19.28^{\circ} \mathrm{C}\right)$

with the coefficient of determination $r^{2}=0.970$. Deviations between values given by this equation and measurements are normally distributed random quantities at the $95 \%$ confidence level (SI1). The remarkable independence of $q_{\mathrm{h}}$ and $T_{\mathrm{h}}$ from a gradually rising water temperature (Fig. 4(b) was caused by selfadjustment of the bubble size. As Fig. 4(c, d) show, data points in Fig. 3 on the bubble height to width ratio $\mathrm{h} / \mathrm{w}$ and the fraction of water vapor in the bubble $\Delta V / V$ being plotted against $T_{S}$ fell within a relatively narrow band for all heating regimes up to $T_{s} \sim 80^{\circ} \mathrm{C}$. While the bubble size increased with $T_{s}$, the fraction of water vapor in the bubble tended to decrease. Fig. 4(e) illustrates the dependence of the bubble volume and cap surface area normalized by bubble height to width ratio $2 \mathrm{~h} / \mathrm{w}$ ratio; the bubble base diameter was about $2 \mathrm{~mm}$ in flight and on Earth. Data points for 

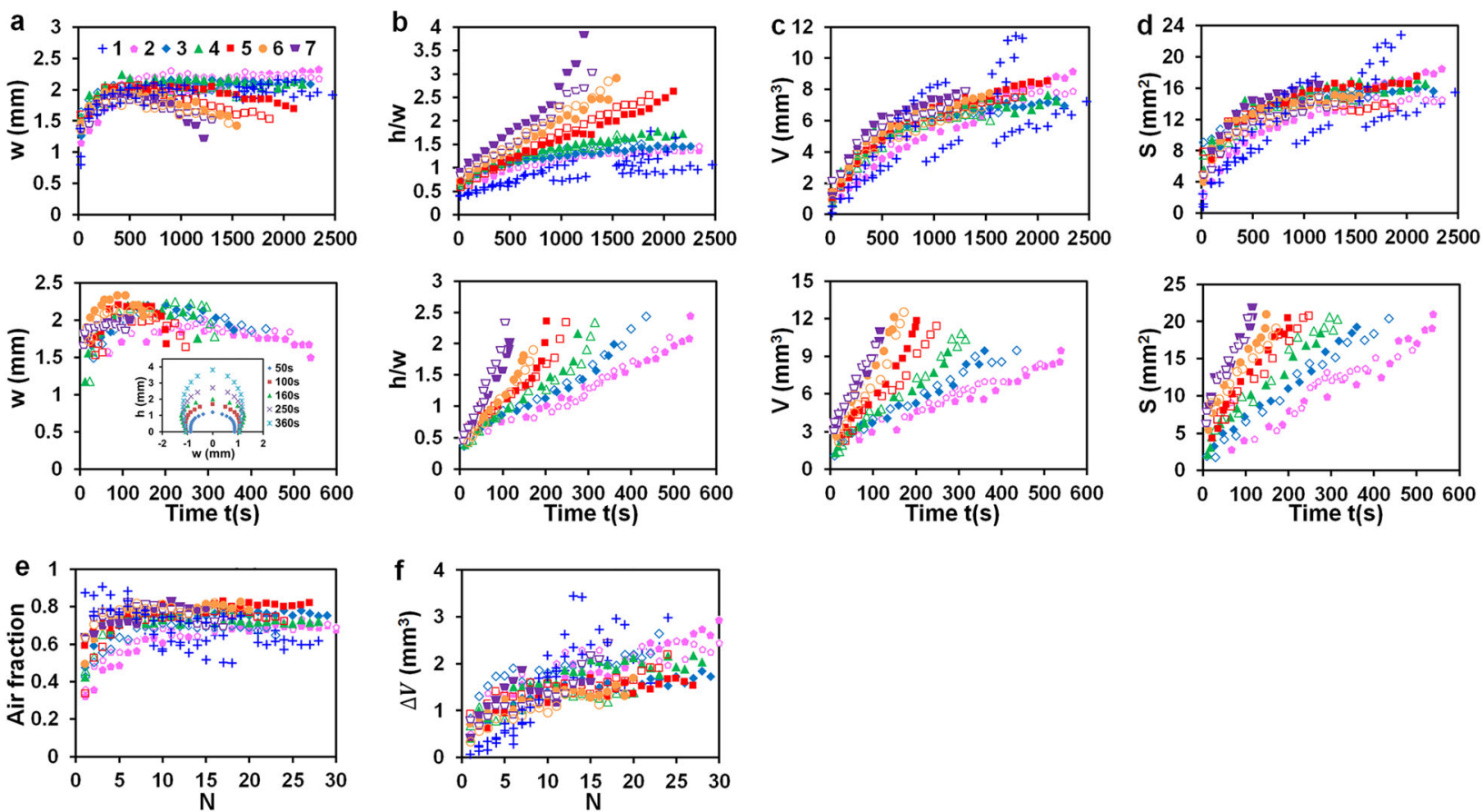

Fig. 3 Thermal regimes. a-d Bubble width $\mathrm{w}$, height $\mathrm{h}$, ratio $\mathrm{h} / \mathrm{w}$, volume $\mathrm{V}$, and cap surface area $\mathrm{S}$ in heating period; curves terminate after departure of the first bubble: Flight $1,20 \mathrm{~V} \mathrm{DC} \& 3 \mathrm{kV} / 20 \mathrm{~Hz} ; 22.4 \mathrm{~V} \mathrm{DC} \mathrm{\&} 4 \mathrm{kV} / 20 \mathrm{~Hz} ; 22.4 \mathrm{~V} \mathrm{DC} \& 4 \mathrm{kV} / 10 \mathrm{~Hz}$, pulses applied in freefall and switched off during acceleration; Earth 2-7, heating cycles $20 \mathrm{~s}$ on/60 s off (top row) and continuous heating (bottom row) with $4 \mathrm{kV} / 20 \mathrm{~Hz}$ pulses (empty symbols) and without HV pulses (filled symbols); applied V DC: 15 (2); 20 (3); 22.4 (4); 25 (5); 30 (6); 35 (7); inset $20 \mathrm{~V}$ DC. e, f Changes of the bubble volume $\Delta V$ due to water vapor condensation as heating was turned off and the air fraction in the bubble $(1-\Delta V / V)$ vs. the number $\mathrm{N}$ of heating cycles for regimes listed in $(\mathbf{a}-\mathbf{d}) . \mathrm{V}, \mathrm{S}$, and $\Delta \mathrm{V}$ were computed by integration of the shape profile along the bubble image (SI1). Results of statistical analysis of measurements are listed in SI1

flight experiments fell close to the curve for a spherical cap and data for all experiments on Earth grouped together below this curve. A bubble residing on the heater eventually divided into two parts by forming a large bubble that departed from the heater and a small bubble pinned to the heater. The remaining bubble grew to about the same size and then divided by forming another departing bubble. This process repeated itself several dozens of times, each time faster and faster, and finally produced a vapor plume whose size was increasing with water temperature (Fig. 2 (b) C, images at $360 \mathrm{~s}$ and $420 \mathrm{~s}, \mathrm{SI}$, video2). The lifetime of the first bubble formed on the heater after applying DC voltage was much longer for heating cycles than for continuous heating due to a slowly rising water temperature (Fig. 4(f). For both heating modes, the departure of this bubble occurred in the range of liquid bulk temperatures $\mathrm{T}_{\mathrm{s}} \sim 50-80^{\circ} \mathrm{C}$ and showed the same dependence on the heat flux (Fig. $4 \mathrm{f}$ inset, SI1):

$$
T_{\mathrm{s}}\left({ }^{\circ} \mathrm{C}\right)=(27.2 \pm 0.93) q_{\mathrm{h}}\left(\mathrm{MW} / \mathrm{m}^{2}\right)+44.96 \pm 1.13^{\circ} \mathrm{C}
$$

with the coefficient of determination $r^{2}=0.966$. Deviations between values given by this equation and measurements are normally distributed random quantities at the $95 \%$ confidence level (SI1).

Flow velocities around a pinned bubble shown in Fig. 5 were computed by tracking individual tiny bubbles formed in flight (seen in Fig. 2a) and beads seeded in the water in Earth experiments. Two toroidal eddies circulating around the bubble in the opposite directions were formed in flight (Fig. 5a). They pushed the hot water away from the bubble interface into the bulk and the cooler water from the bulk toward the bubble base with velocity $\sim 1-3 \mathrm{~mm} / \mathrm{s}$. Similar eddies and a narrow vertical plume, rising from the bubble top with the velocity nearly twice greater than in the vortex flows, appeared under heating on Earth (Fig. 5b-e). However, the plume contribution to the heat flux was remarkably insignificant (Fig. 4(a). The vortex flows intensity slightly increased with increasing the applied DC voltage and decreased as the heating was turned off. Application of HV pulses made the vortex flows more stable. In flight and on Earth, the top of a pinned bubble was observed to oscillate (SI3, video2) at frequencies $v_{b} \sim 2-4 \mathrm{~Hz}$ with amplitude $A_{b}$ that increased with water temperature from $10-30 \mu \mathrm{m}$ at $\mathrm{T}_{\mathrm{s}} \sim 25^{\circ} \mathrm{C}$ to $100 \mu \mathrm{m}$ at $\mathrm{T}_{\mathrm{s}} \sim$ $80^{\circ} \mathrm{C}$ and was not affected by $\mathrm{HV}$ pulses. Velocities of bubble oscillations $\sim v_{b} A_{b}=(20-120) \mu \mathrm{m} / \mathrm{s}$ were much smaller than vortex flow velocities (Fig. 5).

The basic feature of a single-bubble boiling recorded in our experiments is the appearance of a large bubble that is staying for minutes on a relatively small heater on Earth $\left(L_{h} / L_{c} \sim 0.8\right)$ and in flight $\left(\mathrm{L}_{h} / \mathrm{L}_{\mathrm{c}} \sim 0.08\right)$ up to $280^{\circ} \mathrm{C}$ at the water bulk temperature up to $80^{\circ} \mathrm{C}$ (Fig. 4). This bubble behavior was not observed in previous studies of water boiling on relatively large and small heaters under normal and low gravity. Specifically, bubbles of a similar size were reported at high heat fluxes and low subcooling in boiling water on large horizontal flat heaters on Earth $\left(L_{h} /\right.$ $\left.L_{c} \geq 1\right)^{26-30}$ They formed via vigorous lateral coalescence among small bubbles and departed from the heater in less than $\sim$ 0.1-0.3 s. In parabolic flights, bubble liftoff diameters from about $2 \mathrm{~mm}$ to $20 \mathrm{~mm}$ were observed in boiling water on flat heaters for $L_{h} / L_{c} \sim 1.8^{31}$ and $\sim 3.7 .^{32}$ However, these bubbles formed, grew and departed in about 10-12 s. Depending on the level of subcooling, several different modes of boiling water on thin horizontal wires were observed in experiments on Earth ${ }^{33-41}$ for $\mathrm{L}_{\mathrm{h}} / \mathrm{L}_{\mathrm{c}} \sim 0.0046-0.370$, and in drop towers and parabolic flights ${ }^{42-44}$ for $L_{h} / L_{c} \sim 0.0009-0.0030$, where $L_{h}$ is the wire radius: large bubble boiling, coexisting boiling, and explosive small bubble boiling. In particular, raising the heater temperature for saturated boiling under normal ${ }^{33}$ and low gravity ${ }^{42}$ gradually increased the heat flux and the size of a vapor bubble covering the wire until it became totally blanked. As a result, the local maxima and minima in the 

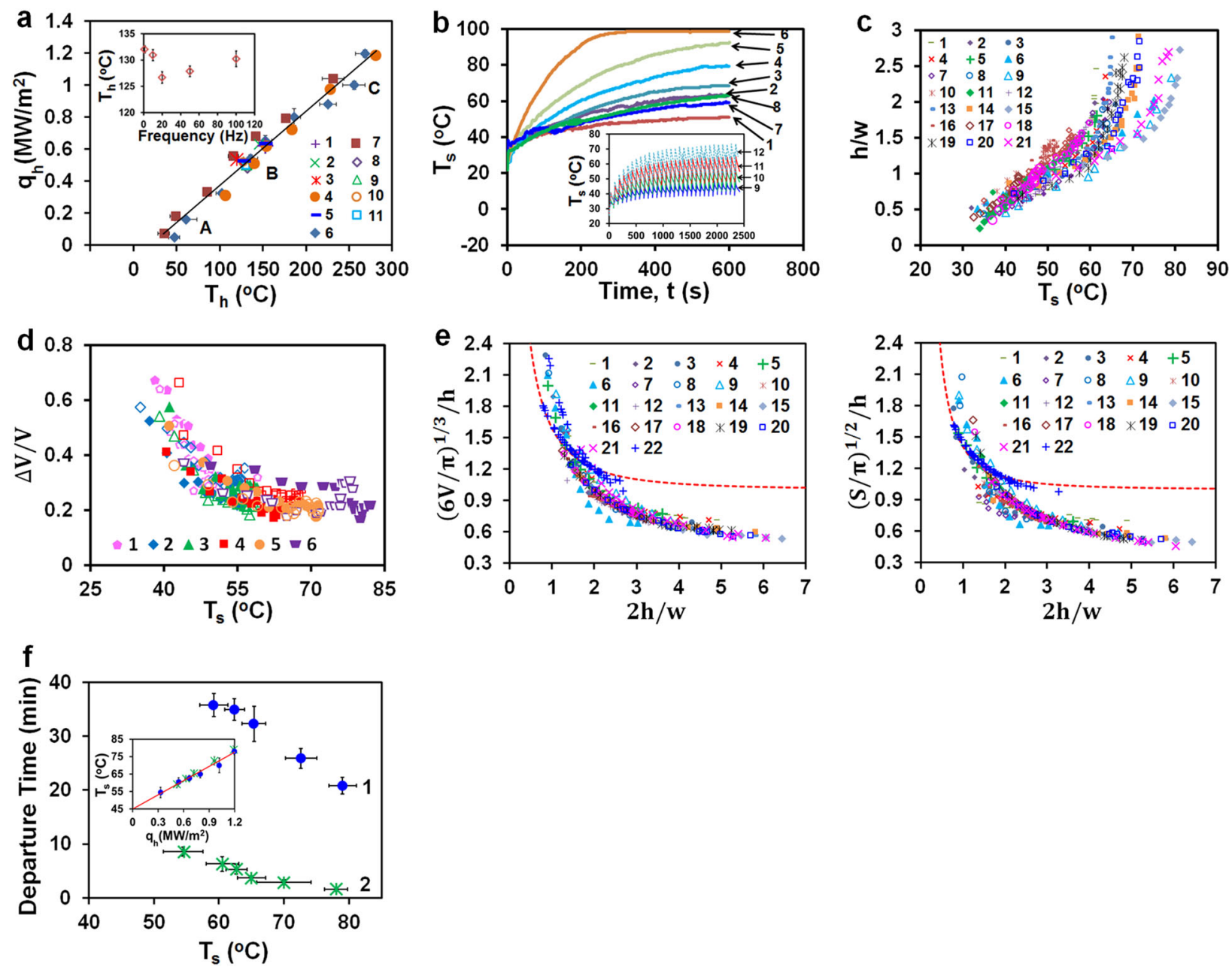

Fig. 4 Effects of increasing heating DC voltage: a Stabilized heat flux $\mathrm{q}_{\mathrm{h}} \mathrm{vs}$. heater temperature $\mathrm{T}_{\mathrm{h}}$. Flight: 1, $20 \mathrm{~V} \mathrm{DC} \& 3 \mathrm{kV} / 20 \mathrm{~Hz} ; 2,22.4 \mathrm{~V}$ DC \& $4 \mathrm{kV} / 20 \mathrm{~Hz} ; 3,22.4 \mathrm{~V} \mathrm{DC} \& 4 \mathrm{kV} / 10 \mathrm{~Hz}$; Earth, heating cycles $20 \mathrm{~s}$ on/60 s off: 4, no HV pulses (points for 15, 20, 22.4, 25, 30, 35 V DC); 5, with $4 \mathrm{kV} / 20 \mathrm{~Hz}$ pulses (points for 20, 22.4 V DC); Earth, continuous heating: 6 , no HV pulses (points for 5, 10, 15, 20, 22.4, 25, 27.5, 30, 35 V DC); 7, with $4 \mathrm{kV} / 20 \mathrm{~Hz}$ pulses (points for 5, 10, 15, 20, 22.4, 25, $30 \mathrm{~V} \mathrm{DC}) ; 8-11$, $20 \mathrm{~V}$ DC with $4 \mathrm{kV}$ pulses at 1 (8); 10 (9); 50 (10); 100 (11) Hz. Points A, B, C mark regimes in Fig. 2b. Inset: Earth, continuous heating $20 \mathrm{~V} \mathrm{DC}: \mathrm{T}_{\mathrm{h}} \mathrm{Vs}$. frequency of $4 \mathrm{kV}$ pulses. $\mathbf{b}$ Earth, $\mathrm{T}_{\mathrm{s}}$, continuous heating: without $\mathrm{HV}$ pulses for 15 (1), 20 (2), 22.4 (3), 25 (4), 30 (5), 35 (6) V DC and with 4 kV/20 Hz pulses for 20 (7), 22.4 (8) V DC. Inset: heating cycles 20 s on/60 s off without HV pulses for: 15 (9), 20 (10), 25 (11), 30 (12) V DC. c Earth, bubble height to width ratio h/w vs. Ts for continuous heating: no HV pulses for 15 (1), 20 (2); 22.4 (3), 25 (4); 30 (5); 35 (6) V DC and with 4 kV/20 Hz pulses for 20 (7), 22.4 (8), 35 (9) V DC; heating cycles $20 \mathrm{~s}$ on/60 s off: no HV pulses for 15 (10), 20 (11), 22.4 (12), 25 (13), 30 (14), 35 (15) V DC and with 4 kV/20 Hz pulses for 15 (16), 20 (17), 22.4 (18), 25 (19), 30 (20), 35 (21) V DC. d Earth, relative changes of bubble volume $\Delta V / V$ as heating turned off vs. $T_{s}$ for heating cycles $20 \mathrm{~s}$ on/60 s off with $4 \mathrm{kV} /$ $20 \mathrm{~Hz}$ pulses (empty symbols) and without HV pulses (filled symbols): 15 (1), 20 (2), 22.4 (3), 25 (4), 30 (5), 35 (6) V DC. (e) The bubble volume V and cap surface area $\mathrm{S}$ normalized by the bubble height $\mathrm{h}$ vs. bubble height to width ratio $2 \mathrm{~h} / \mathrm{w}$ for experiments on Earth, 1-21 as listed in (c), and in flight 22: $20 \mathrm{~V}$ DC \& $3 \mathrm{kV} / 20 \mathrm{~Hz} ; 22.4 \mathrm{~V} \mathrm{DC} \& 4 \mathrm{kV} / 20 \mathrm{~Hz} ; 22.4 \mathrm{~V} \mathrm{DC} \& 4 \mathrm{kV} / 10 \mathrm{~Hz}$. The dashed line represents the spherical cap. (f) Earth, times of bubble departure vs. liquid temperature $T_{s}$ for 1 , heating cycles $20 \mathrm{~s}$ on/ $60 \mathrm{~s}$ off and 2, continuous heating. Points for $15 \mathrm{~V} D C$ (only for regime 2 as a bubble remained on the heater after 40 min of cycles), 20, 22.4, 25, 30, $35 \mathrm{~V} \mathrm{DC}$ (data with and without $4 \mathrm{kV} / 20 \mathrm{~Hz}$ pulses within error bars) arranged from left to right. Inset: $T_{s} v s$. heat flux. Results of statistical analysis of measurements are listed in SI1. Error bars in (a) and (f) represent standard deviations

curve heat flux vs. heater temperature for saturated boiling on Earth were found to vanish $\mathrm{at}^{33} \mathrm{~L}_{\mathrm{h}} / \mathrm{L}_{\mathrm{c}} \leq 0.0096$. However, the formation of a large single bubble engulfing the wire was not observed in the Space Shuttle experiments ${ }^{45}$ on subcooled boiling at $L_{h} / L_{c} \sim 0.0003$. But instead, a set of discreet bubbles formed on a wire, grew up to $4-6 \mathrm{~mm}$ and departed within about $10 \mathrm{~min}$. An abrupt transition from the formation of individual bubbles which sprang from the heating surface in all radial directions to the formation of a thick, stable vapor film over the entire cylindrical heater was recorded for saturated boiling in parabolic flight ${ }^{46}$ at $\mathrm{L}_{\mathrm{h}} / \mathrm{L}_{\mathrm{c}} \sim 0.17$. The lateral motion of bubbles over the heating surface leading to their coalescence were observed in subcooled boiling on single and twisted submillimeter wires on Earth ${ }^{35-41}$ and in parabolic flights. ${ }^{43,44}$ Bubbles with diameters ranging from about 0.01 to $1.6 \mathrm{~mm}$ and departing from the heater in $\sim 0.1$ to $0.3 \mathrm{~s}$ on Earth and $\sim 1-18 \mathrm{~s}$ in flight were recorded in these experiments. Depending on the heat flux and subcooling level, bubbles staying on a heater were observed to eject liquid, vapor-liquid or fog-like jets flowing with velocities $\sim 0.5-15 \mathrm{~cm} / \mathrm{s}$ into the bulk liquid. ${ }^{35-44}$ In ground experiments, the jets formed in the direction opposite to the gravity vector whereas in low gravity they formed in both directions from the wire. ${ }^{44}$ These jets were concluded to be one of the important factors for overall heat transfer in subcooled boiling and the thermoscapillary force due to an interfacial temperature gradient (the Marangoni effect) was suggested as the dominant mechanism of jet formation. ${ }^{35-44}$ In contrast, a liquid plume rising 

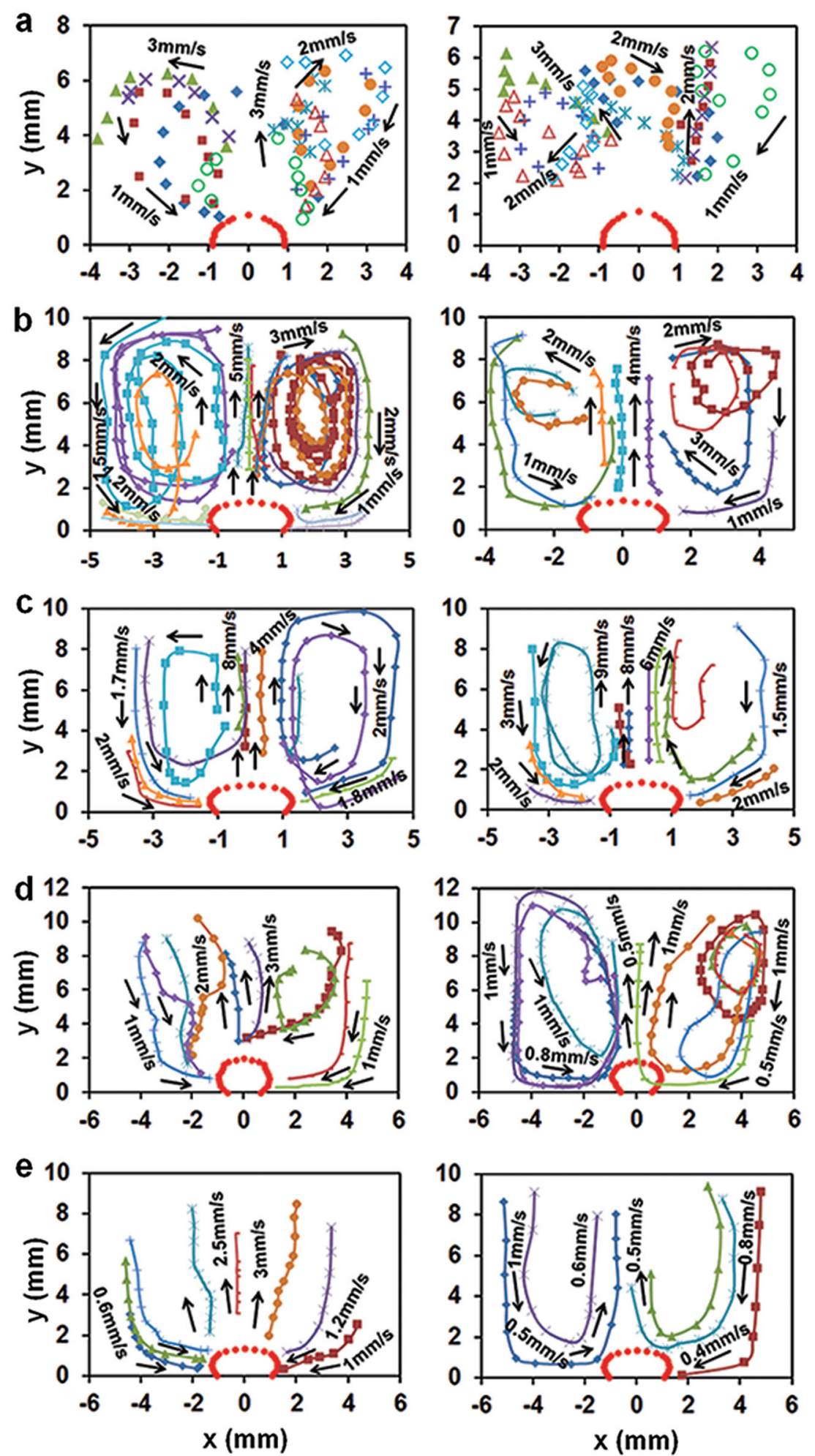

Fig. 5 Flow patterns in the cuvette vertical plane: a Flight, left: freefall, $22.4 \mathrm{~V} \mathrm{DC}$ with $4 \mathrm{kV} / 20 \mathrm{~Hz}$ pulses; right: acceleration, no heating and pulses. b, c Earth, continuous heating: b 22.4 DC, c $30 \mathrm{~V} \mathrm{DC}$; with $4 \mathrm{kV} / 20 \mathrm{~Hz}$ pulses (left), without pulses (right). d, e Earth, heating cycles $20 \mathrm{~V}$ DC $20 \mathrm{~s}$ on/60 s off: d with $4 \mathrm{kV} / 20 \mathrm{~Hz}$ pulses; e without HV pulses; heating ON (left), OFF (right). Symbols indicate trajectories of 10 individual microbubbles for a and individual $75-90 \mu \mathrm{m}$ blue polyethylene microspheres $\left(1.00 \mathrm{~g} / \mathrm{cm}^{3}\right.$, Cospheric, Santa Barbara, CA) on Earth: b 12 particles for left and 11 for right; c 12 for left and right; d 10 for left and right; e 8 for left and 5 for right

from the bubble top was observed only in our ground experiments (Fig. 5) and its contribution to the heat flux appeared to be insignificant (Fig. 4(a).

\section{DISCUSSION}

Presented results demonstrate that energy was transferred away from the heater by evaporating water at the bubble base, condensing vapor on the bubble cap, and then by circulating flow 
a
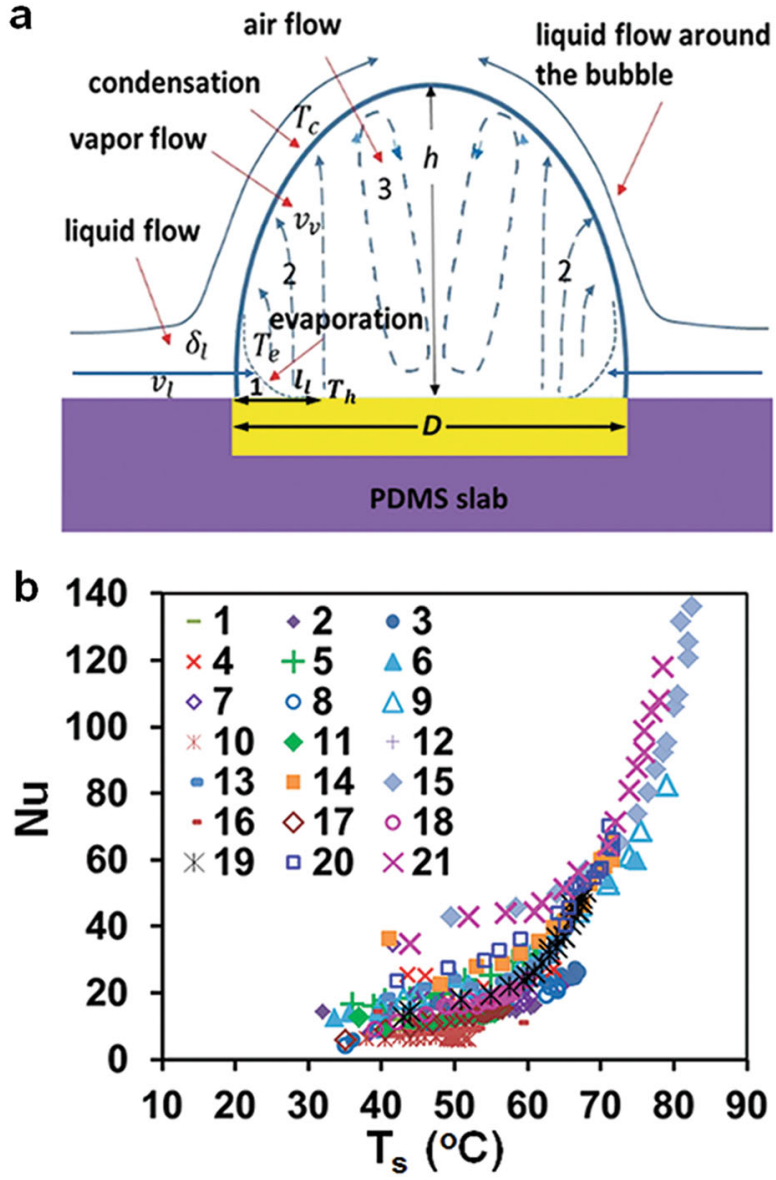

Fig. 6 a Schematic of single-bubble boiling: 1, layer of thickness $\delta_{1}$ and length $I_{1}$ at the bubble footprint where cold liquid flowing into the bubble with velocity $v_{1}$ vaporizes; 2 , vapor streaming toward the bubble cap with velocity $v_{v} ; 3$, non-condensable air constituents accumulating away from the bubble cap; $T_{\mathrm{e}}$ and $T_{\mathrm{c}}$, evaporation and condensation temperatures; $h$ and $D$, bubble height and base diameter. b Earth, the Nusselt number Nu for heat transfer between bubble cap and surrounding liquid vs. $T_{\mathrm{s}}$ for continuous heating and heating cycles, 1-21 as listed in Fig. 4c

to the bulk water. To evaluate basic parameters needed for understanding physical mechanisms underlying the energy transfer, we use data in Figs. 3 and 4 at $T_{\mathrm{h}}=155^{\circ} \mathrm{C}, a_{\mathrm{h}}=$ $0.6 \mathrm{MW} / \mathrm{m}^{2}$ taken as characteristic and properties of water and air $^{47-51}$ (listed in SI1) at the saturation temperature of water $T_{\text {sat }}=$ $100^{\circ} \mathrm{C}$ at $1 \mathrm{~atm}$, also as characteristic.

\section{Flows of vapor and air inside the bubble}

The mass flow rate of liquid evaporating inside the bubble can be estimated as $\dot{\mathrm{m}}_{\mathrm{v}}=\mathrm{q}_{\mathrm{h}} \mathrm{S}_{\mathrm{h}} / \mathrm{h}_{\mathrm{fg}} \sim 1.2 \mathrm{mg} / \mathrm{s}$ since the contribution of energy to heat the liquid flowing into the bubble and cool the condensate formed on the bubble cap is relatively small $c_{p l}\left(T_{\text {sat }}-T_{r}\right) / h_{f g} \sim 0.14$, where $c_{p l}$ and $h_{f g}$ are the water specific heat capacity and latent-heat of vaporization and the room temperature $T_{r} \approx 25^{\circ} \mathrm{C}$. A liquid flows into the bubble over the heated surface at the bubble footprint in the layer whose thickness $\delta_{1}$ (Fig. 6a) can be evaluated from the mass balance $\delta_{1} \sim \dot{m}_{v} / \pi D \rho_{1} v_{1} \sim 0.2 \mathrm{~mm}$ by taking $\mathrm{D} \sim 2 \mathrm{~mm}$ for the bubble base diameter and $v_{1} \sim 1 \mathrm{~mm} / \mathrm{s}$ for the liquid velocity according to data in Fig. 5. The time it takes to heat this liquid is $\mathrm{t}_{1} \sim \delta_{1}^{2} / a_{1} \sim 0.2 \mathrm{~s}, \mathrm{a}_{1}$ is the water thermal diffusivity. When the temperature of this liquid rises above $T_{\text {sat, }}$ tiny vapor bubbles would form and grow with a velocity of the order of several of $\mathrm{m} / \mathrm{s}$ since the Jacob number $J a_{h}=\rho_{1} c_{p l}\left(T_{h}-T_{\text {sat }}\right) / \rho_{v} h_{f g} \sim 164$ corresponds to the inertia dominated regime. ${ }^{52-55}$ Once reaching the liquid surface, they burst and release vapor into the bubble interior. The length of the thin liquid-vapor region at the bubble footprint (1 in Fig. 6a) through which heat is transferred away from the heater can be estimated as $I_{1} \sim v_{1} t_{1} \sim 0.24 \mathrm{~mm}$. To evaluate variation of the local temperature across the heater, we took the solution of a steadystate conduction problem for the temperature of a rectangular heater from which heat is conducted outside through its edges. ${ }^{56}$ In this case, the maximum and minimum local temperatures are respectively achieved at the heater center and the edges. Calculations presented in SI1 indicate that a difference between these values and the average heater temperature $T_{h}$ increased from about $0.35^{\circ} \mathrm{C}$ to $4.5^{\circ} \mathrm{C}$ with raising $\mathrm{T}_{\mathrm{h}}$ from $100^{\circ} \mathrm{C}$ to $270{ }^{\circ} \mathrm{C}$ in our experiments (Fig. 4(a).

Estimates for the mass flux and velocity of the vapor formed in a thin layer at the bubble footprint (1 in Fig. 6a) yield $j_{v} \sim \dot{m}_{v} /$

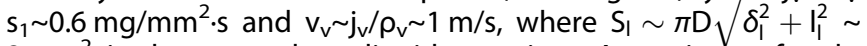
$2 \mathrm{~mm}^{2}$ is the area where liquid vaporizes. An estimate for the velocity of condensate formed on the bubble cap of area $\mathrm{S}$ $10 \mathrm{~mm}^{2}$ (data in Fig. $3 \mathrm{~d}$ ) $\mathrm{v}_{\mathrm{lc}} \sim \dot{\mathrm{m}}_{\mathrm{v}} / \rho_{1} \mathrm{~S} \sim 0.1 \mathrm{~mm} / \mathrm{s}$ shows that vapor condensation does not drive the liquid circulation around the bubble as $v_{l c}$ is substantially smaller than flow velocities in Fig. 5 .

Non-condensable air constituents (oxygen and nitrogen) brought by the liquid into the bubble are carried with the streaming vapor toward the bubble cap and remain there while the vapor condenses. The diffusive flux of the air away from the bubble surface can balance the vapor flow only within a thin layer of thickness $\sim \mathrm{d}_{\mathrm{a}} / \mathrm{v}_{\mathrm{v}} \sim 40 \mu \mathrm{m}, \mathrm{d}_{\mathrm{a}}$ is the diffusion coefficient of air constituents in water vapor (SI1). As the volume of this layer $\sim d_{a} S$ / $v_{v}$ is much smaller than the air volume in the bubble (data in Fig. $3 e, c)$, air carried with the streaming vapor would accumulates away from the bubble cap (region 3 in Fig. 6a). Driven by the vapor flowing along the bubble cap (region 2 in Fig. 6a), the velocity with which the air circulates inside the bubble is $v_{a} \sim v_{v} \sim$ $1 \mathrm{~m} / \mathrm{s}$. Flow of vapor and air is laminar as the Reynolds numbers are $\operatorname{Re}_{\mathrm{v}} \sim \varrho_{\mathrm{v}} \mathrm{v}_{\mathrm{v}} \mathrm{h} / \eta_{\mathrm{v}} \sim 120$ and $\operatorname{Re}_{\mathrm{a}} \sim \varrho_{\mathrm{a}} \mathrm{v}_{\mathrm{a}} \mathrm{h} / \eta_{\mathrm{a}} \sim 120$, where $\mathrm{h} \sim$ $3.6 \mathrm{~mm}$ is the bubble height (data in Fig. $3 b$ ) and $\varrho_{v}, \eta_{v}$ and $\varrho_{a}, \eta_{a}$ are the vapor and air density and dynamic viscosity. An estimate for the vapor volume $\mathrm{I}_{1} \mathrm{~S} \sim 2.4 \mathrm{~mm}^{3}$ is consistent with data on a change in the bubble volume $\Delta \mathrm{V}$ in Fig. 3f caused by vapor condensation. The time to replenish the vapor condensed as the heating is turned off $\sim \rho_{v} l_{1} S / \dot{m}_{v} \sim 1.2 \mathrm{~s}$ is also consistent with observed changes of the bubble size in heating cycles in flight and on Earth (data in Fig. 2a, c).

Once the three-phase contact line along the liquid layer inside a bubble resides on the well-wetted heater surface, the vapor region would be located above the heater surface as the interior contact angle is smaller than $90^{\circ}$ (Fig. 6a). If the bubble grows by moving the liquid layer beyond the heater edge, vapor would come in contact with the PDMS surface since the interior contact angle of water on the hydrophobic PDMS surface is larger than $90^{\circ}$. This situation can occur only when the PDMS temperature is greater than the dew point of water vapor. Otherwise, the bubble would shrink due to vapor condensation. This negative feedback facilitates anchoring of a bubble to the heater if the temperature of the surrounding surface is below the dew point.

\section{Flow of liquid around the bubble}

It is laminar as the Reynolds number is $\operatorname{Re}_{\mathrm{I}} \sim \varrho_{\mathrm{l}} \mathrm{v}_{\mathrm{I}} \mathrm{h} / \eta_{\mathrm{I}} \sim 12$, where the liquid velocity $v_{1} \sim 1 \mathrm{~mm} / \mathrm{s}$ (data in Fig. 5 ) and $\eta_{1}$ is the liquid dynamic viscosity. This flow might be generated by the surface tension force along the bubble $\operatorname{cap}^{3,8,14-17,57}$ due to the temperature variation $\Delta T_{b}$ or by the shear stress exerted on the liquid-bubble interface by the flow of vapor and air inside the bubble. It is conceivable that both factors operate during the heating period, whereas the flow of vapor and air ceases 
when the heating is switched off (data in Fig. $5 d$, e). The stress balance at the bubble surface for the former $\eta_{1} v_{1} / h \sim\left(d \gamma_{1} / d T\right) \Delta T_{b} / h$ yields $\Delta T_{b} \sim 1.5 \times 10^{-3}{ }^{\circ} \mathrm{C} \ll T_{h}-T_{r}$. For the latter $\eta_{1} v_{1} / h \sim \eta_{v} v_{v, t} / h$ and/or $\eta_{1} v_{1} / h \sim \eta_{a} v_{a, t} / h$, it yields $1-2 \mathrm{~cm} / \mathrm{s}$ for the velocity of vapor $v_{v, \tau}$ and air $v_{a, \tau}$ tangent to the liquid-bubble interface that is much smaller that the velocity of vapor and air inside the bubble $\sim 1 \mathrm{~m} /$ s.accomo These estimates indicate that the liquid flow around the bubble is highly sensitive to subtle processes at the bubble cap and requires a more careful study.

\section{Heat transfer at the bubble cap}

To estimate temperatures of the liquid-vapor region $\mathrm{T}_{\mathrm{e}}$ and at the bubble cap $T_{c}$ (Fig. 6a), we used the Hertz-Knudsen equation for the vapor mass flux $j_{v}$ with the accommodation coefficient $\xi \sim 0.01$ -0.1 for stagnant water surfaces. ${ }^{58}$ Calculations presented in SI1 yield $\mathrm{T}_{\mathrm{e}} \approx 114{ }^{\circ} \mathrm{C}, \mathrm{T}_{\mathrm{c}} \approx 96{ }^{\circ} \mathrm{C}$ for $\xi \sim 0.01$ and $\mathrm{T}_{\mathrm{e}} \approx 101{ }^{\circ} \mathrm{C}, \mathrm{T}_{\mathrm{c}} \approx 99.7{ }^{\circ} \mathrm{C}$ for $\xi \sim 0.1$. As the bubble cap temperature for both values of $\xi$ is close to $T_{\text {sat }}$ and $T_{s}$ represents the bulk liquid temperature, the Nusselt number for heat transfer from the bubble cap to the surrounding liquid on Earth can be evaluated as

$\mathrm{Nu}=\mathrm{q}_{\mathrm{h}} \mathrm{S}_{\mathrm{h}} \mathrm{h} / \mathrm{k}_{\mathrm{l}} \mathrm{S}\left(\mathrm{T}_{\mathrm{sat}}-\mathrm{T}_{\mathrm{s}}\right)$

where $k_{1}$ is the liquid thermal conductivity and variations of the heat flux at the bubble cap $q_{h} S_{h} / S$ and the bubble height $h$ with $T_{s}$ were computed using data on $q_{h}, S$ and $h$ at a fixed applied voltage in Fig. 3. Remarkably, values of $\mathrm{Nu}$ plotted in Fig. $6 \mathrm{~b}$ for both heating regimes lie within a relatively narrow band, increasing with $T_{s}$ from about 20 at room temperature to 140 at $\mathrm{T}_{\mathrm{s}} \sim 80^{\circ} \mathrm{C}$. We compared these values with the data predicted by correlations for convective heat transfer from a vapor bubble of diameter condensing in a flow of subcooled water ${ }^{59,60}$ and the buoyancy convection heat transfer from the cap of a solid hemisphere. ${ }^{61}$ The former yielded $\mathrm{Nu} \sim 2.5$ and the latter Nu 11 for our experimental conditions (see SI1). These estimates clearly demonstrate that another mechanism contributes to energy transfer from the bubble cap to the surrounding liquid.

We attribute large values of Nu in Fig. $6 \mathrm{~b}$ to periodic injection of a vapor-air mixture from the bubble caused by periodic overheating of the liquid layer near the bubble cap. Taking $\mathrm{j}_{\mathrm{c}} \mathrm{h}_{\mathrm{fg}}$ with $\mathrm{j}_{\mathrm{c}} \sim-\mathrm{S}_{1} \mathrm{j}_{\mathrm{v}} / \mathrm{S}$ for the heat flux of vapor condensing on the bubble cap, the time period and length it takes to heat the cool liquid flowing with the velocity $v_{1}$ along the bubble cap from $T_{r}$ to $T_{c}$ can be estimated using the energy balance equation as $t_{c} \sim$ $\pi \mathrm{Ja}_{\mathrm{c}}^{2} \mathrm{a}_{\mathrm{l}} / 4 \mathrm{v}_{\mathrm{vc}}^{2} \sim 0.15 \mathrm{~s}$ and $\mathrm{v}_{1} \mathrm{t}_{\mathrm{c}} \sim 0.15 \mathrm{~mm}$, where $\mathrm{Ja}_{\mathrm{c}}=\rho_{1} \mathrm{c}_{\mathrm{pl}}\left(\mathrm{T}_{\mathrm{c}}-\mathrm{T}_{\mathrm{r}}\right) /$ $\rho_{\mathrm{v}} \mathrm{h}_{\mathrm{fg}} \sim 210$ and $v_{\mathrm{vc}} \sim \mathrm{j}_{\mathrm{c}} / \rho_{\mathrm{v}} \sim 0.2 \mathrm{~m} / \mathrm{s}$. When the local liquid temperature rises above $T_{c}$, the rate of vapor condensation decreases and the local gas pressure under the bubble cap builds up, eventually jetting vapor mixed with air into the surrounding liquid. Once the layer of overheated liquid is blown away from the bubble cap and replaced by a colder liquid, the liquid temperature at this spot drops down below $T_{c}$ causing the rate of vapor condensation to increase and thereby to stop gas injection. Then, the local liquid temperature begins to rise and the process repeats itself again and again. The estimate for the frequency of local overheating $1 / t_{c} \sim 7 \mathrm{~Hz}$, correlates well with the frequency range of bubble cap oscillations observed in flight and ground experiments. In low gravity, periodic injection of a vapor-air mixture created circulating tiny bubbles (Fig. 2a and SI2, video1) whose stability in the bulk liquid was caused by the residual air. On Earth, it generated plumes rising through the bulk liquid and releasing the trapped air by bubbling at the water surface ( $\mathrm{SI} 3$, video2). In both cases, the rate of heat transfer from the bubble was drastically enhanced by increasing the area of the vapor-liquid interface. The proposed mechanism is consistent with the observation that Nu given by Eq. (3) (Fig. 6b) depends only on the water temperature. The flow circulation time within the cuvette $t_{f} \sim 20 \mathrm{~s}$ (Fig. 5) is sufficient for the liquid flowing away from the bubble to transfer the acquired heat to the bulk by thermal conduction across closed streamlines as the characteristic length $\sqrt{2 a_{1} t_{f}} \sim 3 \mathrm{~mm}$ is comparable to half the cuvette width. Note that the frequency range of local liquid overheating is lower by more than an order of magnitude compared to intense capillary waves causing the violent emission of micrometer-sized bubbles from a condensing vapor bubble in the so-called microbubble emission boiling (MEB) regime. ${ }^{55,62-64}$

\section{Bubble growth and detachment}

Bubble evolution is mainly governed by normal stresses at the bubble interface since the contribution of tangential stresses estimated above is relatively small. The normal stresses include the surface tension pressure, liquid hydrostatic pressure, and dynamic pressures of liquid and condensing vapor. The role of the dynamic pressure of liquid flow driven by the bubble growing at the timescale of the order of minutes (Fig. 3a-d) is insignificant as the ratio between its value and the surface tension pressure $4 \gamma_{1} / D$ is $\sim 2 \times 10^{-6}$. The contribution of the vapor dynamic pressure can be neglected ${ }^{65-68}$ only if the ratio $\rho_{v} \dot{V}_{v}^{2} / \pi^{2} D^{3} \gamma_{l}$ is smaller than $2.5 \times 10^{-6}$, where $V_{v}=\mathrm{q} S_{h} / \rho_{v} h_{f g}$ is the vapor flow rate inside the bubble. An extremely low flow rate is required because the vapor velocity increases rapidly when the bubble neck shrinks radially. In our experiments at $T_{h}>100^{\circ} \mathrm{C}$ where $q_{h}$ was varying from 0.3 to $1.2 \mathrm{MW} / \mathrm{m}^{2}$ (Fig. 4 a), this ratio ranging from $1.3 \times 10^{-4}$ to $2.1 \times 10^{-3}$ exceeded significantly this limitation. Nevertheless, the quasistatic equation for a pinned bubble ${ }^{65-68}$ that considers only the surface tension and hydrostatic pressures provides some understanding of the bubble behavior. In particular, the dimensionless solution of this equation predicts that the bubble shape is fully characterized by its relative height $2 \mathrm{~h} / \mathrm{D}$ and the Bond number Bo $=\left(\mathrm{D} / 2 \mathrm{~L}_{\mathrm{c}}\right)^{2}$. In boiling, the bubble height is determined by the thermal balance across the bubble cap that is expressed in terms of $\mathrm{Nu}$ specified by $T_{s}$ (Fig. 6b). This feature explains why dimensionless characteristics of bubbles in ground experiments plotted against $T_{\mathrm{s}}$ for various values of $q$ but all with Bo 0.16 for $100{ }^{\circ} \mathrm{C}$ would group together (Fig. 4c, d). It also explains a more elongated shape of bubbles observed in ground experiments compared to a spherical shape of bubbles formed in flight at Bo $1.6 \times 10^{-3}$ (Fig. 4e). Within the framework of the quasi-static equation, the greatest value of the relative bubble height $2 \mathrm{~h}_{\max } / D$ at a particular value of Bo for which the neck becomes zero is assumed to represent a bubble that divides into two parts in the neck region, one forming a departing bubble and the other a new pinned bubble. ${ }^{66-68}$ Expressions ${ }^{67,68}$ for the bubble at zero neck predict height $h_{\max }=5.4 \mathrm{~mm}$ with the width $3.1 \mathrm{~mm}$ and volume $V_{d}=26.4 \mathrm{~mm}$ for Bo 0.16 and $\mathrm{D} \sim 2 \mathrm{~mm}$ occurred in our ground experiments. While we observed a similar mode of bubble departure, a bubble at this instant was more elongated and its volume was two-three times smaller, depending on the heating regime (Fig. 3c). These estimates and experimental data on the bubble departure time (Fig. 4f, Eq. 2) indicate that the bubble pinch-off was strongly influenced by the vapor flow rate at the bubble base that is determined by the heat flux.

In conclusion, single-bubble boiling of water on a millimetersized well-wetted heater was recorded under normal gravity and low gravity in parabolic flights. The gravity contribution to the heat transfer was insignificant. The lifetime of a bubble on the heater varied from 1 to about $40 \mathrm{~min}$, depending on the heating mode and water temperature. Due to self-adjustment of the bubble size, the heat flux provided by boiling rose linearly up to about $1.2 \mathrm{MW} / \mathrm{m}^{2}$ with increasing heater temperature and was not affected by a gradually rising water temperature. The application of high-voltage pulses increased the heat flux by about $10 \%$ at the same heater temperature. Estimates of basic flow and heat transfer parameters provided insight into physical mechanisms underlying single-bubble boiling. As the rate of heat transfer from 
the bubble cap exceeded predictions of convective models by more than an order of magnitude, it was attributed to periodic injection of a vapor-air mixture from the bubble to the surrounding liquid. While the quasi-static model for the bubble growth explained similarity in dependence of the bubble shape on water temperature for different heating regimes, the observed bubble pinch-off was strongly influenced by the vapor flow rate at the bubble base.

The fast response and stable operation of single-bubble boiling over a broad range of temperatures pave the way for development of new devices to control heat transfer by forming surface domains with distinct thermal properties and wettability. The bubble lifetime can be adjusted by changing the water temperature. The ability of heating water on millimeter scales far above $100^{\circ} \mathrm{C}$ without an autoclave or a powerful laser provides a new approach for processing of biomaterials and chemical reactions. The replacement of PDMS with high-temperature insulation would make it possible to increase the heater temperature to $320-350{ }^{\circ} \mathrm{C}$ needed to initiate the spinodal decomposition of water.

\section{METHODS}

Flight and ground experiments were conducted in a rectangular UV-Vis quartz cuvette, Cole-Parmer, Chicago, IL (Fig. 1) equipped with a thin-film (1.3 $\mathrm{mm}$ thick) temperature resistance sensor (Innovative Sensor Technology, Las Vegas, NV). A PDMS slab ( 6.3 mm thick) mounted at the cuvette bottom was fabricated from Sylgard 184, Dow Corning, Midland, MI. Heating DC voltage was provided with DIGI-35A and DIGI-185 (Electro Industries, Chicago, IL) and Hewlett Packard 6207B /Agilent 6207B. The voltage drop in electric circuits (Fig. 1) was recorded at $500 \mathrm{~Hz}$ with the data acquisition system U6-Pro Data Logger, LabJack, Lakewood, CO. The bubble motion was recorded at $13.95 \mathrm{fps}$ with a DCC1545M-USB 2.0 CMOS camera, Thorlabs, Newton, NJ. The temperature below the water surface was recorded in ground experiments with a data logger TW-23039-64, Type K, Cole-Parmer, IL. HV pulses were generated with an amplifier Model 10/40 (slew rate $0.75 \mathrm{kV} / \mu \mathrm{s}$ ) Trek, Lockport, NY and an Agilent Waveform Generator Model 33220a. The conditions of 31 experiments (3 in flights and 28 on Earth), the number of experiments replicated for the same heating regime, mean and standard deviations for the heat flux, heater temperature and bubble departure time, and the description and results of common statistical tests used for analysis of measurements to demonstrate the reproducibility of data are listed in SI1, Section 2. All measurements were included in the analysis.

\section{DATA AVAILABILITY}

The datasets generated during the current study are available from the corresponding author on reasonable request.

\section{ACKNOWLEDGEMENTS}

We are grateful to Yelena Khusid for help in design and fabrication of the setup for flight and Earth's experiments and Dana Qasem for participation in parabolic flights. This work was supported in part by NASA's Physical Science Research Program (grant NNX13AQ53G), NASA's Game Changing Development Program (grant NNX12AM26G), and NASA/New Jersey Institute of Technology Space Act Agreement.

\section{AUTHORS CONTRIBUTIONS}

E.E. contributed to development of the setup for flight and Earth's experiments, performed Earth's experiments, and analyzed data. Y.S. developed the setup for Earth's experiments. J.T. contributed to development of the flight setup, performed flight experiments, and assisted in Earth's experiments. Q.L. assisted in Earth's experiments and analysis of data. B.K. initiated and directed the project, contributed to development of the setup for flight and Earth's experiments, performed flight experiments, and analyzed data. All authors discussed the results and participated in writing the manuscript.

\section{ADDITIONAL INFORMATION}

Supplementary information accompanies the paper on the npj Microgravity website (https://doi.org/10.1038/s41526-018-0055-y).

Competing interests: The authors declare no competing interests.

Publisher's note: Springer Nature remains neutral with regard to jurisdictional claims in published maps and institutional affiliations.

\section{REFERENCES}

1. Mudawar, I. Assessment of high-heat-flux thermal management schemes. IEEE Trans. Compon. Packag. Tech. 24, 122-141 (2001).

2. Zhang, H., Mudawar, I. \& Hasan, M. Application of flow boiling for thermal management of electronics in microgravity and reduced-gravity space systems. IEEE Trans. Compon. Packag. Technol. 32, 466-477 (2009).

3. Dhir, V. K. Boiling heat transfer. Annu. Rev. Fluid. Mech. 30, 365-401 (1998).

4. Workshop on Critical Issues in Microgravity Fluids, Transport, and Reaction Processes in Advanced Human Support Technology, Report No. NASA/TM-2004212940 (NASA Glenn Research Center, 2004).

5. Recapturing a Future for Space Exploration: Life and Physical Sciences Research for a New Era (National Academies Press, 2011).

6. Pioro, I. L., Rohsenow, W. \& Doerffer, S. S. Nucleate pool-boiling heat transfer. I: review of parametric effects of boiling surface. Int. J. Heat. Mass Transf. 47, 5033-5044 (2004).

7. Pioro, I. L., Rohsenow, W. \& Doerffer, S. S. Nucleate pool-boiling heat transfer. II: assessment of prediction methods. Int. J. Heat. Mass Transf. 47, 5045-5057 (2004).

8. Straub, J. Boiling heat transfer and bubble dynamics in microgravity. Adv. Heat Transf. 35, 57-172 (2001).

9. Kim, J., Benton, J. F. \& Wisniewski, D. Pool boiling heat transfer on small heaters: effects of gravity and subcooling. Int. J. Heat. Mass Transf. 45, 3921-3934 (2002).

10. Di Marco, P. Review of reduced gravity boiling heat transfer: European research. Int. J. Microgravity Sci. Appl. 20, 252-263 (2003).

11. Kim, J. Review of reduced gravity boiling heat transfer: US research. Int. J. Microgravity Sci. Appl. 20, 264-271 (2003).

12. Ohta, H. Review of reduced gravity boiling heat transfer: Japanese research. Int. J. Microgravity Sci. Appl. 20, 272-285 (2003).

13. Straub, J. \& Zell, M. Transport-mechanisms in natural nucleate boiling in absence of external forces. Heat. Mass Transf. 46, 1147-1157 (2010).

14. Raj, R., Kim, J. \& McQuillen, J. Subcooled pool boiling in variable gravity environments. ASME J. Heat Transfer 131, (1-10 (2009). 091502-.

15. Raj, R., Kim, J. \& McQuillen, J. Gravity scaling parameter for pool boiling heat transfer. ASME J. Heat Transfer 132, (1-9 (2010). 091502-.

16. Raj, R. \& Kim, J. Heater size and gravity based pool boiling regime map: transition criteria between buoyancy and surface tension dominated boiling. ASME J. Heat Transfer 132, (1-10 (2010). 091503-.

17. Raj, R., Kim, J. \& McQuillen, J. On the scaling of pool boiling heat flux with gravity and heater size. ASME J. Heat Transfer 134, (1-13 (2012). 011502-.

18. Di Marco, P. Influence of force fields and flow patterns on boiling heat transfer performance: a review. ASME J. Heat Transfer 134, (1-15 (2012). 030801-.

19. Barrett, R. T. Fastener Design Manual, NASA Reference Publication 1228 (Lewis Research Center, 1990).

20. Carslaw, H. S., \& Jaeger, J. C., Conduction of Heat in Solids, 2nd Ed (Oxford Univ. Press, 1959).

21. Di Marco, P. \& Grassi, W. Effects of external electric field on pool boiling: Comparison of terrestrial and microgravity data in the ARIEL experiment. Exp. Therm. Fluid Sci. 35, 780-787 (2011).

22. Di Marco, P., Raj, R. \& Kim, J. Boiling in variable gravity under the action of an electric field: results of parabolic flight experiments. J. Phys. Conf. Ser. 327, 1-14 (2011). 012039-

23. Bari, S. D. \& Robinson, A. J. Adiabatic bubble growth in uniform DC electric fields. Exp. Therm. Fluid Sci. 44, 114-123 (2013).

24. Di Marco, P., Kurimoto, R., Saccone, G., Hayashi, K. \& Tomiyama, A. Bubble shape under the action of electric forces. Exp. Therm. Fluid Sci. 49, 160-168 (2013).

25. Saville, D. A. Electrohydrodynamics: The Taylor-Melcher leaky dielectric model. Annu. Rev. Fluid. Mech. 29, 27-64 (1997).

26. Chu, I.-C., No, H. C. \& Song, C.-H. Visualization of boiling structure and critical heat flux phenomenon for a narrow heating surface in a horizontal pool of saturated water. Int. Int. J. Hear Mass Transf. 62, 142-152 (2013).

27. Chu, I.-C., No, H. C., Song, C.-H. \& Euh, D. J. Observation of critical heat flux mechanism in horizontal pool boiling of saturated water. Nucl. Eng. Des. 279, 189-199 (2014). 
28. Kim, H., Park, Y. \& Buongiorno, J. Measurement of wetted area fraction in subcooled pool boiling of water using infrared thermography. Nucl. Eng. Des. 264, 103-110 (2013).

29. Ahn, H. S. \& Kim, M. K. Visualization study of critical heat flux mechanism on a small and horizontal copper heater. Int. J. Multiph. Flow. 41, 1-12 (2012).

30. Goel, P., Nayaka, A. K., Kulkarni, P. P. \& Joshi, J. B. Experimental study on bubble departure characteristics in subcooled nucleate pool boiling. Int. J. Multiph. Flow. 89, 163-176 (2017).

31. Oka, T., Abe, Y., Mori, Y. H. \& Nagashima, A. Pool boiling of n-pentane, CFC-113, and water under reduced gravity: parabolic flight experiments with a transparent heater. ASME J. Heat Transfer 117, (408-417 (1995).

32. Qiu, D. M. et al. Single-bubble dynamics during pool boiling under low gravity conditions. J. Thermophys. Heat. Transf. 16, 336-345 (2002).

33. Bakhru, N. \& Lienhard, J. H. Boiling from small cylinders. Int. J. Heat. Mass Transf. 15, 2011-2025 (1972)

34. Inoue, T., Kawae, N. \& Monde, M. Effect of subcooling on critical heat flux during pool boiling on a horizontal heated wire. Heat. Mass Transf. 33, 481-488 (1998).

35. Wang, H., Peng, X. F., Wang, B. X. \& Lee, D. J. Jet flow phenomena during nucleate boiling. Int. J. Heat. Mass Transf. 45, 1359-1363 (2002).

36. Wang, H., Peng, X. F., Wang, B. X. \& Lee, D. J. Bubble sweeping and jet flows during nucleate boiling of subcooled liquids. Int. J. Heat. Mass Transf. 46, 863-869 (2003).

37. Wang, H., Peng, X. F., Lin, W. K., Pan, C. \& Wang, B. X. Bubble-top jet flow on microwires. Int. J. Heat. Mass Transf. 47, 2891-2900 (2004).

38. Wang, H., Peng, X. F., Christopher, D. M., Lin, W. K. \& Pan, C. Investigation of bubble-top jet flow during subcooled boiling on wires. Int. J. Heat. Fluid Flow. 26, 485-494 (2005).

39. Zhou, L., Du, X., Yang, Y., Jiang, P. \& Wang, B. Thermocapillary effect on bubble sweeping and circling during subcooled nucleate pool boiling of water over microwire. J. Heat. Mass Transf. 88, 276-283 (2015).

40. Lu, J. F., Peng, X. F. \& Bourouga, B. Nucleate boiling modes of subcooled water on fine wires submerged in a pool. Exp. Heat. Tran. 19, 95-111 (2006).

41. Lu, J. F. \& Peng, X. F. Bubble jet flow formation during boiling of subcooled water on fine wires. Int. J. Heat. Mass Transf. 50, 3966-3976 (2007).

42. Fukada, Y., Haze, I. \& Osakabe, M. The effect of fouling on nucleate pool boiling of small wires. Heat. Transf. Asian Res. 33, 316-329 (2004).

43. Munro, T. R., Koeln, J. P., Fassmann, A. W., Barnett, R. J. \& Ban, H. Phase change heat transfer and bubble behavior observed on twisted wire heater geometries in microgravity. Int. J. Heat. Fluid Flow. 47, 21-30 (2014).

44. Munro, T. R. \& Ban, H. Flow and heat flux behavior of micro-bubble jet flows observed in thin, twisted-wire, subcooled boiling in microgravity. Microgravity Sci. Technol. 27, 49-60 (2015).

45. Koeln, J. P., Boulware, J. C., Ban, H. \& Dennison, J. Observations on braided thin wire nucleate boiling in microgravity. Int. J. Heat. Fluid Flow. 32, 973-981 (2011).

46. Shatto, D. P. \& Peterson, G. P. Pool boiling critical heat flux in reduced gravity. ASME J. Heat. Transf. 121, 865-873 (1999).

47. Green, D. W. \& Perry, R. H. Perry's Chemical Engineers' Handbook, 8th Ed (McGrow Hill, 2007).

48. Lide, D. R. (ed). CRC Handbook of Chemistry and Physics, 84th Ed (CRC Press, 2003).

49. Haynes, W. M. (ed). CRC Handbook of Chemistry and Physics, 95th Ed (CRC Press, 2014).

50. Fuller, E. N., Schettler, P. D. \& Glddlngs, J. D. A new method for prediction coefficients of binary gas - phase diffusion. Ind. Eng. Chem. 58, 19-27 (1966).
51. Welty, J. R., Rorrer, G. L. \& Foster, D. G. Fundamentals of Momentum, Heat, and Mass Transfer, 6th Ed (Wiley, 2014).

52. Lee, H. S. \& Merte, H. Spherical vapor bubble growth in uniformly superheated liquids. Int. J. Heat. Mass Transf. 39, 2427-2447 (1996).

53. Lee, H. S. \& Merte, H. Hemispherical vapor bubble growth in microgravity: experiments and model. Int. J. Heat. Mass Transf. 39, 2449-2461 (1996).

54. Robinson, A. J. \& Judd, R. L. The dynamics of spherical bubble growth. Int. J. Heat. Mass Transf. 47, 5101-5113 (2004).

55. Prosperetti, A. Vapor bubbles. Annu. Rev. Fluid. Mech. 49, 221-248 (2017).

56. Arpaci, V. S. Conduction Heat Transfer, Ch 4 (Addison-Wesley, 1966).

57. Petrovic, S., Robinson, T. \& Judd, R. L. Marangoni heat transfer in subcooled nucleate pool boiling. Int. J. Heat. Mass Transf. 47, 5115-5128 (2004).

58. Marek, R., J. \& Straub, J. Analysis of the evaporation coefficient and the condensation coefficient of water. Int. J. Heat. Mass Transf. 44, 39-53 (2001).

59. Warrier, G. R., Basu, N. \& Dhir, V. K. Interfacial heat transfer during subcooled flow boiling. Int. J. Heat. Mass Transf. 45, 3947-3959 (2002).

60. Bejan, A. Convection Heat Transfer, 4th Ed (John Wiley \& Son, 2013).

61. Lewandowski, W. M. et al. Theoretical and experimental study of natural convection heat transfer from isothermal hemisphere. Int. J. Heal Mass Transf. 40, 101-109 (1997).

62. Suzuki, K., Saitoh, H. \& Matsumoto, K. High heat flux cooling by microbubble emission boiling. Ann. N. Y. Acad. Sci. 974, 364-377 (2002).

63. Wang, G. \& Ping Cheng, P. Subcooled flow boiling and microbubble emission boiling phenomena in a partially heated microchannel. Int. J. Heal Mass Transf. 52, 79-91 (2009).

64. Ueno, I., Ando, J., Koiwa, Y., Saiki, T. \& Kaneko, T. Interfacial instability of a condensing vapor bubble in a subcooled liquid. Eur. Phys. J. Spec. Top. 224, 415-424 (2015).

65. Gerlach, D., Biswas, G., Durst, F. \& Kolobaric, V. Quasi-static bubble formation on submerged orifices. Int. J. Heat. Mass Transf. 48, 425-438 (2005).

66. Lesage, F. J., Cotton, J. S. \& Robinson, A. J. Analysis of quasi-static vapour bubble shape during growth and departure. Phys. Fluids 25, 1-21 (2013). 067103-.

67. Lesage, F. J. \& Marois, F. Experimental and numerical analysis of quasi-static bubble size and shape characteristics at detachment. Int. J. Heal Mass Transf. 64, 53-69 (2013).

68. Bari, S. D. \& Robinson, A. J. Experimental study of gas injected bubble growth from submerged orifices. Exp. Therm. Fluid. Sci. 44, 124-137 (2013).

(i) Open Access This article is licensed under a Creative Commons Attribution 4.0 International License, which permits use, sharing, adaptation, distribution and reproduction in any medium or format, as long as you give appropriate credit to the original author(s) and the source, provide a link to the Creative Commons license, and indicate if changes were made. The images or other third party material in this article are included in the article's Creative Commons license, unless indicated otherwise in a credit line to the material. If material is not included in the article's Creative Commons license and your intended use is not permitted by statutory regulation or exceeds the permitted use, you will need to obtain permission directly from the copyright holder. To view a copy of this license, visit http://creativecommons. org/licenses/by/4.0/.

(c) The Author(s) 2018 